\title{
(2) OPEN ACCESS \\ Compensation of retinal nerve fibre layer thickness as assessed using optical coherence tomography based on anatomical confounders
}

\author{
Jacqueline Chua @ 1 , Florian Schwarzhans, ${ }^{2}$ Duc Quang Nguyen, ${ }^{3}$ Yih Chung Tham, ${ }^{1}$ \\ Josh Tjunrong Sia, ${ }^{1}$ Claire Lim, ${ }^{1}$ Shivani Mathijia, ${ }^{3}$ Carol Cheung (1), ${ }^{4}$ Aung Tin, ${ }^{5}$ \\ Georg Fischer, ${ }^{2}$ Ching-Yu Cheng $(1),{ }^{3}$ Clemens Vass, $^{6}$ Leopold Schmetterer (i) ${ }^{7}$
}

\begin{abstract}
- Additional material is published online only. To view please visit the journal online (http://dx.doi.org/10. 1136bjophthalmol-2019314086)
\end{abstract}

For numbered affiliations see end of article.

Correspondence to Professor Leopold Schmetterer Department of Clinical Pharmacology, Medical University of Vienna, Vienna 1090, Austria; leopold. schmetterer@seri.com.sg

$J C$ and FS are joint first authors.

Received 15 February 2019

Revised 4 April 2019 Accepted 27 April 2019

Published Online First 22 May 2019

\section{Check for updates}

(C) Author(s) (or their employer(s)) 2020. Re-use permitted under CC BY-NC. No commercial re-use. See rights and permissions. Published by BMJ.

\section{To cite: Chua J,}

Schwarzhans F, Nguyen DQ, et al. Br 1 Ophthalmol

2020:104:282-290.

\section{ABSTRACT}

Background/Aims To compensate the retinal nerve fibre layer (RNFL) thickness assessed by spectral-domain optical coherence tomography (SD-OCT) for anatomical confounders.

Methods The Singapore Epidemiology of Eye Diseases is a population-based study, where 2698 eyes (1076 Chinese, 704 Malays and 918 Indians) with high-quality SD-OCT images from individuals without eye diseases were identified. Optic disc and macular cube scans were registered to determine the distance between fovea and optic disc centres (fovea distance) and their respective angle (fovea angle). Retinal vessels were segmented in the projection images and used to calculate the circumpapillary retinal vessel density profile. Compensated RNFL thickness was generated based on optic disc (ratio, orientation and area), fovea (distance and angle), retinal vessel density, refractive error and age. Linear regression models were used to investigate the effects of clinical factors on RNFL thickness.

Results Retinal vessel density reduced significantly with increasing age $(1487 \pm 214 \mu \mathrm{m}$ in $40-49,1458 \pm 208 \mu \mathrm{m}$ in $50-59,1429 \pm 223 \mu \mathrm{m}$ in $60-69$ and $1415 \pm 233 \mu \mathrm{m}$ in $\geq 70$ ). Compensation reduced the variability of RNFL thickness, where the effect was greatest for Chinese $(10.9 \% ; p<0.001)$, followed by Malays (6.6\%; $p=0.075)$ and then Indians (4.3\%; $p=0.192$ ). Compensation reduced the age-related RNFL decline by $55 \%$ in all participants $(\beta=-3.32 \mu \mathrm{m}$ vs $\beta=-1.50 \mu \mathrm{m} / 10$ years; $p<0.001$ ). Nearly $62 \%$ of the individuals who were initially classified as having abnormally thin RNFL (outside the 99\% normal limits) were later reclassified as having normal RNFL.

Conclusions RNFL thickness compensated for anatomical parameters reduced the variability of measurements and may improve glaucoma detection, which needs to be confirmed in future studies.

\section{INTRODUCTION}

Glaucoma is the leading cause of blindness worldwide $^{1}$ and reduction of retinal nerve fibre layer (RNFL) thickness imaged with optical coherence tomography (OCT) is an early hallmark of glaucoma. ${ }^{2}$ Despite significant improvements with OCT, there remain limitations in relation to its use for glaucoma diagnosis. ${ }^{3}$ First, the OCT modality does not adjust for ocular biometry and morphology such as optic disc (size and area) and disc-fovea angle, ${ }^{4-6}$ retinal vessel position, ${ }^{6-8}$ refractive error ${ }^{79}$ and axial length, ${ }^{10}$ which can reduce the precision of RNFL thickness measurement. Second, retinal vessels reduce with age, systemic comorbidities ${ }^{11}$ and also in glaucoma. ${ }^{12}$ This further complicates matter when RNFL thickness measured from OCT devices also includes retinal vessels. Hence, the thinning of measured RNFL may also represent the narrowing of retinal vessels. Overall, an imprecise RNFL thickness may result in an inaccurate clinical assessment of glaucoma.

We developed a comprehensive multivariate model which compensates the influence of anatomical parameters as mentioned above and showed it improved the limits of RNFL variability in healthy eyes. ${ }^{13}$ However, this model was tested on a small sample of healthy predominantly young Caucasians. Population-based data on the normal RNFL variability of a multiethnic population are vital, because these are more generalisable and less susceptible to selection biases. Singapore consists of people of Chinese, Malaysian and Indian ancestries, with interethnic difference in central corneal thickness, ${ }^{14}$ corneal biomechanics, ${ }^{15}{ }^{16}$ RNFL thickness, ${ }^{17}$ macular thickness, ${ }^{18}$ retinal vessels, ${ }^{19}$ refractive error $^{20}$ and axial length. ${ }^{20}$ Hence, this multiethnic Asian population presents as an attractive sample to examine the effectiveness of this model, and may potentially impact the utility of RNFL normative databases.

In this study, we applied a model which compensates the RNFL thickness for anatomical parameters, ${ }^{13}$ on a multiethnic Asian population-based sample, free of ocular diseases and also investigated the associations with demographic and clinical factors. We hypothesised that after compensating for anatomical parameters, the interindividual variability of compensated RNFL will be reduced and anatomical factors that were initially correlated with measured RNFL will be attenuated.

\section{METHODS}

\section{Study participants}

Participants were enrolled from the Singapore Epidemiology of Eye Diseases (SEED) programme, comprising Chinese, Malays and Indians aged 40-80 years. Study methodology was identical and has been described elsewhere. ${ }^{21-23}$ Data were derived from 2698 participants, of which 1076 




Figure 1 Flow chart of the inclusion and exclusion criteria of study eyes. Systematic selection process identified 2698 eyes, comprising 1076 Chinese, 704 Malays and 918 Indians with high-quality spectral-domain optical coherence tomography (SD-OCT) images from individuals without eye diseases for analysis. SCES, Singapore Chinese Eye Study; SEED, Singapore Epidemiology of Eye Diseases; SIMES, Singapore Malay Eye Study; SINDI, Singapore Indian Eye Study.

were Chinese (year 2009-2011), 704 Malays (year 2010-2014) and 918 Indians (year 2013-2015). All study participants were provided with written informed consent in adherence to the Declaration of Helsinki.

\section{Ocular examinations}

Participants underwent an ocular examination including visual acuity, subjective refraction, slit-lamp biomicroscopy, gonioscopy, intraocular pressure (IOP) measurement using Goldmann applanation tonometry, measurement of central corneal thickness using an ultrasound pachymeter (CCT Advent; Mentor O \& O, Norwell, USA), corneal curvature and refractive error using an autorefractor (Canon RK-5 Autorefractor Keratometer; Canon, Japan), axial length using non-contact partial coherence interferometry (IOL Master V3.01, Carl Zeiss Meditec, Germany) and posterior segment examination at the slit-lamp using a 78 dioptre lens. ${ }^{14}$

\section{Other measurements}

Detailed interviewer-administered questionnaire was used to collect demographic data, medication and ocular surgery histories. Blood pressure was measured using a digital automatic blood pressure monitor (Dinamap model Pro Series DP110X-RW, GE Medical Systems Information Technologies, Milwaukee). ${ }^{24}$ 
Non-fasting venous blood samples were collected for biochemistry analysis. Diabetes mellitus was defined as random glucose of $\geq 11.1 \mathrm{mmol} / \mathrm{L}$, diabetic medication usage or a physician diagnosis of diabetes. Hypertension was defined as systolic blood pressures $\geq 140 \mathrm{~mm} \mathrm{Hg}$ or diastolic blood pressures $\geq 90 \mathrm{~mm}$ $\mathrm{Hg}$ or physician-diagnosed hypertension or self-reported history of hypertension. Hyperlipidaemia was defined as total cholesterol $\geq 6.2 \mathrm{mmol} / \mathrm{L}$ or self-reported use of lipid-lowering drugs.

\section{OCT imaging}

Participants underwent Cirrus SD-OCT (Carl Zeiss Meditec, Dublin, CA) imaging after pupil dilation. We acquired optic

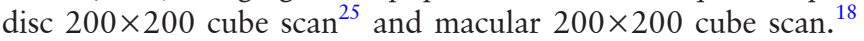
Trained graders masked to the participant characteristics reviewed the quality of OCT scans. Poor-quality images (signal strength less than 6 and/or movement artefacts within the RNFL measurement circle) were excluded from the analysis.

\section{Automated parameter extraction}

Automated parameter extraction was performed, as previously published. ${ }^{13}$ Briefly, we registered the optic disc and macular cube scans of each eye, using an automatic OCT layer segmentation algorithm (Retinal Image Analysis Lab, Iowa Institute for Biomedical Imaging, Iowa City, IA). ${ }^{26-28}$ We then extracted optic disc parameters including its area, orientation (angle between the horizontal axis and the major axis of the optic disc) and ratio (quotient between major and minor axes) from the spectraldomain OCT (SD-OCT). We also segmented the retinal vessel tree from the optic disc and macular images. ${ }^{13}$ We considered all vessels that are within a band of diameter around the centre of the optic disc, extending from 3.28 to $3.64 \mathrm{~mm}$ to integrate a 256-sector vessel profile. The thickness values of all vessels within the same sector were summed up. After which, we generated a semicontinuous profile, similar to RNFL distribution, that expresses vessel density corresponding to the RNFL measurement area, where each individual discrete profile of vessel distribution was convoluted with a Gaussian window, as described previously. ${ }^{29}{ }^{30}$ From the registered image and considering fovea centre as automatically determined in SD-OCT, we obtained the fovea parameters: first, the fovea distance, which corresponds to the distance between optic disc and fovea centres; second, the fovea angle, which corresponds to the angle between a line connecting fovea and optic disc centres and a horizontal line passing through the optic disc centre.

\section{Inclusion/exclusion criteria}

Of the 14908 eyes of 7454 SEED participants, 9735 eyes of 5221 had available OCT data (figure 1). We excluded 2902 eyes due to presence of glaucoma/glaucoma suspect/self-reported glaucoma, ${ }^{31}$ retinopathies ${ }^{32}$ and age-related macular degeneration, ${ }^{33} 2575$ eyes with poor-quality OCT scans and 299 eyes due to missing clinical variables. In total, 3959 eyes of 2698 participants who were without eye diseases had high-quality SD-OCT images. If bilateral OCT data were available for each participant, one eye was randomly selected for subsequent analyses. This left a total of 2698 eyes (2698 participants), including 1076 Chinese eyes (1076 participants), 704 Malay eyes (704 participants) and 918 Indian eyes (918 participants) for analysis.

\section{Statistical analyses}

Primary outcomes were measured and compensated RNFL thickness measurements. Shapiro-Wilk test was used to assess the normality of the distribution of the continuous variables. To compare the variables between groups, one-way analysis of

Table 1 Characteristics of included participants among the three ethnic groups

\begin{tabular}{|c|c|c|c|c|c|}
\hline & All participants & Chinese & Malay & Indian & $P$ value* \\
\hline Participants (n) & 2698 & 1076 & 704 & 918 & \\
\hline Age (years) & $57 \pm 8$ & $54 \pm 7$ & $59 \pm 8$ & $60 \pm 8$ & $<0.001$ \\
\hline Gender, male (\%) & $1367(51)$ & $559(52)$ & $339(48)$ & $469(51)$ & 0.279 \\
\hline Diabetes (\%) & $513(20)$ & $83(8)$ & $159(23)$ & $271(31)$ & $<0.001$ \\
\hline Hypertension (\%) & $1530(57)$ & $504(47)$ & $465(66)$ & $561(61)$ & $<0.001$ \\
\hline Hyperlipidaemia (\%) & $1319(51)$ & $423(40)$ & $373(54)$ & $523(60)$ & $<0.001$ \\
\hline Lens status, pseudophakia (\%) & $183(7)$ & $34(3)$ & $47(7)$ & $102(11)$ & $<0.001$ \\
\hline Intraocular pressure $(\mathrm{mm} \mathrm{Hg})$ & $14.5 \pm 2.7$ & $14.1 \pm 2.8$ & $14.4 \pm 2.7$ & $15.1 \pm 2.5$ & $<0.001$ \\
\hline Central corneal thickness $(\mu \mathrm{m})$ & $545.9 \pm 33.9$ & $552.3 \pm 33.6$ & $541.8 \pm 33.8$ & $541.4 \pm 33.2$ & $<0.001$ \\
\hline Corneal curvature (mm) & $7.6 \pm 0.3$ & $7.7 \pm 0.3$ & $7.6 \pm 0.3$ & $7.6 \pm 0.3$ & 0.001 \\
\hline Clinical vertical cup-to-disc ratio & $0.38 \pm 0.10$ & $0.38 \pm 0.11$ & $0.36 \pm 0.10$ & $0.39 \pm 0.10$ & $<0.001$ \\
\hline Optic disc area $\left(\mathrm{mm}^{2}\right)$ & $1.93 \pm 0.38$ & $1.86 \pm 0.37$ & $2.01 \pm 0.38$ & $1.95 \pm 0.37$ & $<0.001$ \\
\hline Optic disc ratio & $1.13 \pm 0.08$ & $1.13 \pm 0.08$ & $1.13 \pm 0.08$ & $1.12 \pm 0.07$ & 0.009 \\
\hline Optic disc orientation $\left(^{\circ}\right)$ & $98.4 \pm 29.8$ & $96.6 \pm 32.2$ & $99.5 \pm 27.9$ & $99.7 \pm 28.0$ & 0.035 \\
\hline Fovea distance (mm) & $4.47 \pm 0.32$ & $4.54 \pm 0.26$ & $4.54 \pm 0.32$ & $4.33 \pm 0.33$ & $<0.001$ \\
\hline Fovea angle $\left(^{\circ}\right)$ & $-7.3 \pm 4.8$ & $-7.3 \pm 3.4$ & $-7.7 \pm 3.9$ & $-6.8 \pm 6.5$ & $<0.001$ \\
\hline Retinal vessel density $(\mu \mathrm{m})$ & $1452.5 \pm 216.1$ & $1462.8 \pm 211.5$ & $1497.2 \pm 221.4$ & $1406.1 \pm 208.8$ & $<0.001$ \\
\hline $\begin{array}{l}\text { Spherical equivalent refractive error } \\
\text { (dioptres) }\end{array}$ & $-0.3 \pm 2.1$ & $-0.9 \pm 2.3$ & $0.0 \pm 2.0$ & $0.2 \pm 1.8$ & $<0.001$ \\
\hline Axial length (mm) & $23.8 \pm 1.2$ & $24.1 \pm 1.3$ & $23.6 \pm 1.0$ & $23.5 \pm 1.0$ & $<0.001$ \\
\hline Measured RNFL $(\mu \mathrm{m})$ & $93.5 \pm 10.6$ & $96.6 \pm 9.6$ & $96 \pm 9.7$ & $87.8 \pm 9.9$ & $<0.001$ \\
\hline Compensated RNFL ( $\mu \mathrm{m})$ & $95.0 \pm 9.7$ & $97.8 \pm 8.7$ & $96.3 \pm 9.1$ & $90.7 \pm 9.8$ & $<0.001$ \\
\hline Signal strength & $8.1 \pm 1.1$ & $8.4 \pm 1.0$ & $8.1 \pm 1.1$ & $7.8 \pm 1.1$ & $<0.001$ \\
\hline
\end{tabular}

Data are number (\%) or mean \pm SD, as appropriate.

* $P$ value was obtained with one-way analysis of variance for continuous variables and with $\chi^{2}$ tests for categorical variables. RNFL, retinal nerve fibre layer. 
Table 2 Characteristics of included participants among the varying age groups

\begin{tabular}{|c|c|c|c|c|c|c|}
\hline & $40-49$ & $50-59$ & $60-69$ & $\geq 70$ & $P$ value* & $\mathbf{P}$ trend $t$ \\
\hline Participants (n) & 504 & 1265 & 714 & 215 & & \\
\hline \multicolumn{7}{|l|}{ Gender (\%) } \\
\hline Male & $242(48)$ & $603(47.7)$ & $387(54.2)$ & $135(62.8)$ & \multirow[t]{2}{*}{$<0.001$} & \multirow[t]{2}{*}{$<0.001$} \\
\hline Female & $262(52)$ & $662(52.3)$ & $327(45.8)$ & $80(37.2)$ & & \\
\hline \multicolumn{7}{|l|}{ Ethnic groups (\%) } \\
\hline Chinese & $371(73.6)$ & $463(36.6)$ & $199(27.9)$ & $43(20)$ & \multirow[t]{3}{*}{$<0.001$} & \multirow[t]{3}{*}{$<0.001$} \\
\hline Malay & $97(19.2)$ & $305(24.1)$ & $222(31.1)$ & $80(37.2)$ & & \\
\hline Indian & $36(7.1)$ & $497(39.3)$ & $293(41)$ & $92(42.8)$ & & \\
\hline Diabetes (\%) & $39(7.9)$ & $225(18.5)$ & $186(27.8)$ & $63(31)$ & $<0.001$ & $<0.001$ \\
\hline Hypertension (\%) & $178(35.4)$ & $629(49.8)$ & $539(75.5)$ & $184(85.6)$ & $<0.001$ & $<0.001$ \\
\hline Hyperlipidaemia (\%) & $155(31.1)$ & $589(47.7)$ & $426(63)$ & $149(73.4)$ & $<0.001$ & $<0.001$ \\
\hline $\begin{array}{l}\text { Lens status, pseudophakia } \\
(\%)\end{array}$ & $3(0.6)$ & $19(1.5)$ & $71(9.9)$ & $90(41.9)$ & $<0.001$ & $<0.001$ \\
\hline Intraocular pressure $(\mathrm{mm} \mathrm{Hg})$ & $14.4 \pm 2.6$ & $14.7 \pm 2.7$ & $14.5 \pm 2.6$ & $13.9 \pm 2.8$ & 0.002 & 0.070 \\
\hline $\begin{array}{l}\text { Central corneal thickness } \\
(\mu \mathrm{m})\end{array}$ & $554.8 \pm 34.5$ & $545.8 \pm 33.2$ & $542.4 \pm 33.8$ & $536.7 \pm 32.8$ & $<0.001$ & $<0.001$ \\
\hline Corneal curvature (mm) & $7.7 \pm 0.3$ & $7.7 \pm 0.3$ & $7.6 \pm 0.3$ & $7.6 \pm 0.3$ & 0.508 & 0.236 \\
\hline $\begin{array}{l}\text { Clinical vertical cup-to-disc } \\
\text { ratio }\end{array}$ & $7.7 \pm 0.3$ & $7.7 \pm 0.3$ & $7.6 \pm 0.3$ & $7.6 \pm 0.3$ & 0.508 & 0.236 \\
\hline Optic disc area $\left(\mathrm{mm}^{2}\right)$ & $1.9 \pm 0.37$ & $1.94 \pm 0.38$ & $1.92 \pm 0.38$ & $1.93 \pm 0.39$ & 0.114 & 0.489 \\
\hline Optic disc ratio & $1.13 \pm 0.08$ & $1.13 \pm 0.08$ & $1.13 \pm 0.08$ & $1.13 \pm 0.08$ & 0.357 & 0.979 \\
\hline Optic disc orientation $\left(^{\circ}\right)$ & $97.6 \pm 31.0$ & $98 \pm 29.3$ & $100.3 \pm 29.3$ & $96.2 \pm 30.9$ & 0.209 & 0.557 \\
\hline Fovea distance (mm) & $4.5 \pm 0.29$ & $4.46 \pm 0.31$ & $4.46 \pm 0.36$ & $4.47 \pm 0.29$ & 0.059 & 0.166 \\
\hline Fovea angle $\left(^{\circ}\right)$ & $-7.5 \pm 4.2$ & $-7.0 \pm 5.2$ & $-7.3 \pm 4.5$ & $-8.0 \pm 4.7$ & 0.011 & 0.293 \\
\hline Retinal vessel density $(\mu \mathrm{m})$ & $1487.3 \pm 213.5$ & $1458 \pm 208.0$ & $1429.3 \pm 222.9$ & $1415.1 \pm 233.1$ & $<0.001$ & $<0.001$ \\
\hline $\begin{array}{l}\text { Spherical equivalent } \\
\text { refractive error (dioptres) }\end{array}$ & $-1.3 \pm 2.3$ & $-0.3 \pm 2.1$ & $0.3 \pm 1.9$ & $0.1 \pm 1.6$ & $<0.001$ & $<0.001$ \\
\hline Axial length (mm) & $24.0 \pm 1.3$ & $23.8 \pm 1.2$ & $23.6 \pm 1.1$ & $23.5 \pm 0.9$ & $<0.001$ & $<0.001$ \\
\hline Measured RNFL $(\mu \mathrm{m})$ & $97.5 \pm 9.9$ & $93.8 \pm 10.4$ & $91.5 \pm 9.8$ & $88.2 \pm 11.5$ & $<0.001$ & $<0.001$ \\
\hline Compensated RNFL ( $\mu \mathrm{m})$ & $97.4 \pm 8.8$ & $94.8 \pm 9.7$ & $94.3 \pm 9.5$ & $93.1 \pm 11.4$ & $<0.001$ & $<0.001$ \\
\hline Signal strength & $8.6 \pm 1.0$ & $8.3 \pm 1.0$ & $7.7 \pm 1.1$ & $7.4 \pm 0.9$ & $<0.001$ & $<0.001$ \\
\hline
\end{tabular}

Data are number (\%) or mean $\pm \mathrm{SD}$, as appropriate.

*P value was obtained with one-way analysis of variance for continuous variables and with $\chi^{2}$ tests for categorical variables.

TP trend was obtained with non-parametric test for trend across ordered groups.

RNFL, retinal nerve fibre layer.

variance and $\chi^{2}$ tests were performed. $\mathrm{P}$ trend was assessed by modelling the median value of the various age groups in the linear regression analysis (non-normally distributed continuous) or with the use of the $\chi^{2}$ test for linear trends (categorical). To compare the variation of the compensated RNFL with the variation when using the conventional approach without compensation, base asymptotic test for the equality of coefficients of variation was used. Linear regression models were used to investigate the effects of demographic and clinical factors (independent variables) on RNFL thickness (dependent variable).

We further classified the 2698 individuals into three categories based on the thickness of their measured RNFL measurements: (1) normal individuals, where $95 \%$ of RNFL measurements fall in the green category (within 95\% of normal limits; $n=2563$ ); (2) suspect, the thinnest 5\% of RNFL measurements fall in the yellow category (within $99 \%$ of normal limits; $n=108$ ); and (3) abnormal individuals, the thinnest $1 \%$ of RNFL measurements fall in the red category (outside of $99 \% ; n=27$ ). We then determined the range (minimum to maximum) of measured RNFL measurements within each category. After which, we applied the same cut-off to the entire distribution of compensated RNFL measurements. We then took note of how many persons were reclassified, that is, 'moved' or stayed within category after

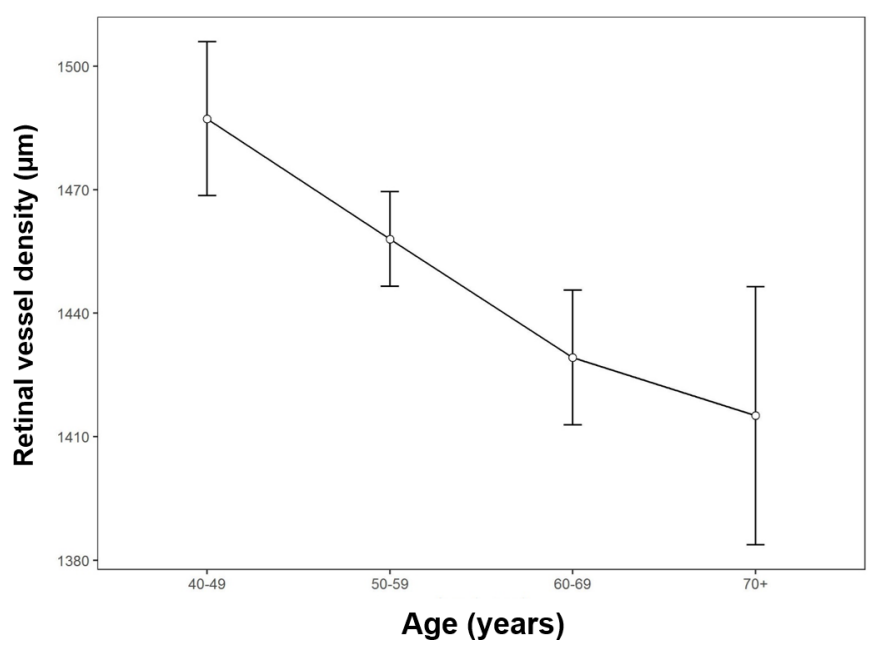

Figure 2 Distribution of retinal vessel density of varying age groups. Retinal vessel density reduced with age. For every 1 year increase in age, there was a $-28.09 \mu \mathrm{m}$ reduction in retinal vessel density in the overall population $(95 \% \mathrm{Cl}-38.23$ to $17.96 ; p<0.001)$. 
Table 3 Coefficient of variations for measured and compensated RNFL thickness values among the three ethnic groups

\begin{tabular}{|c|c|c|c|c|}
\hline & $\begin{array}{l}\text { CoV in } \% \\
\text { measured } \\
\text { RNFL }\end{array}$ & $\begin{array}{l}\text { CoV in } \% \\
\text { compensated } \\
\text { RNFL }\end{array}$ & $\begin{array}{l}\text { Relative } \\
\text { reduction of } \\
\mathrm{CoV} \text { in } \%\end{array}$ & $P$ value* \\
\hline \multicolumn{5}{|c|}{$\begin{array}{l}\text { All } \\
\text { participants }\end{array}$} \\
\hline Inferior & 14.39 & 13.11 & 8.88 & $<0.001$ \\
\hline Superior & 14.77 & 13.40 & 9.33 & $<0.001$ \\
\hline Nasal & 16.21 & 14.90 & 8.11 & $<0.001$ \\
\hline Temporal & 19.45 & 17.16 & 11.79 & $<0.001$ \\
\hline Global & 11.30 & 10.22 & 9.55 & $<0.001$ \\
\hline \multicolumn{5}{|l|}{ Chinese } \\
\hline Inferior & 13.45 & 11.62 & 13.60 & $<0.001$ \\
\hline Superior & 14.16 & 12.44 & 12.18 & $<0.001$ \\
\hline Nasal & 17.42 & 14.70 & 15.63 & $<0.001$ \\
\hline Temporal & 17.44 & 14.92 & 14.46 & $<0.001$ \\
\hline Global & 9.94 & 8.86 & 10.90 & $<0.001$ \\
\hline \multicolumn{5}{|l|}{ Malay } \\
\hline Inferior & 13.55 & 12.57 & 7.26 & 0.049 \\
\hline Superior & 13.91 & 13.08 & 6.00 & 0.107 \\
\hline Nasal & 15.11 & 13.71 & 9.27 & 0.012 \\
\hline Temporal & 16.44 & 16.84 & -2.43 & 0.535 \\
\hline Global & 10.15 & 9.48 & 6.56 & 0.075 \\
\hline \multicolumn{5}{|l|}{ Indian } \\
\hline Inferior & 14.26 & 14.11 & 1.07 & 0.750 \\
\hline Superior & 14.11 & 13.47 & 4.54 & 0.167 \\
\hline Nasal & 15.34 & 15.24 & 0.67 & 0.842 \\
\hline Temporal & 18.21 & 18.96 & -4.11 & 0.238 \\
\hline Global & 11.27 & 10.79 & 4.26 & 0.192 \\
\hline
\end{tabular}

${ }^{*} \mathrm{P}$ value was obtained with base asymptotic test for the equality of coefficients of variation.

CoV, coefficient of variation; RNFL, retinal nerve fibre layer.

compensation. We then examined the concordance of these two classifications. As such, we examined the number of subjects who were erroneously categorised into the risk categories in the measured data set. To examine the impact that compensation had on RNFL thickness classification, a contingency table was used to display the frequency distribution of RNFL thickness reclassification. Data were analysed with statistical software (STATA V13.1; StataCorp).

\section{RESULTS}

The mean \pm SD age of the 2698 participants was $57 \pm 8$ years for Chinese, $59 \pm 8$ years for Malays and $60 \pm 8$ years for Indians $(p<0.001)$ and $51 \%$ were women $(p=0.279$; table 1$)$. Differences between the ethnic groups were found for age, diabetes, hypertension, hyperlipidaemia, lens status, IOP, central corneal thickness (CCT), corneal curvature, clinical vertical cup-to-disc ratio, optic disc and fovea parameters, retinal vessel density, spherical refractive error and axial length $(\mathrm{p}<0.05$; table 1$)$. Compensated RNFL was thicker than measured RNFL for the overall population $(95.0 \pm 9.7 \mu \mathrm{m}$ vs $93.5 \pm 10.6 \mu \mathrm{m} ; \mathrm{p}<0.001)$, Chinese $(97.8 \pm 8.7 \mu \mathrm{m}$ vs $96.6 \pm 9.6 \mu \mathrm{m} ; \mathrm{p}=0.002)$ and Indians $(90.7 \pm 9.8 \mu \mathrm{m}$ vs $87.8 \pm 9.9 \mu \mathrm{m} ; \mathrm{p}<0.001)$ whereas there were no differences between the compensated and measured RNFL for Malays $(96.3 \pm 9.1 \mu \mathrm{m}$ vs $96.0 \pm 9.7 \mu \mathrm{m} ; \mathrm{p}=0.517)$.

Characteristics of the participants were further summarised according to age groups (table 2). Older participants tended to have diabetes, hypertension, hyperlipidaemia, pseudophakia,

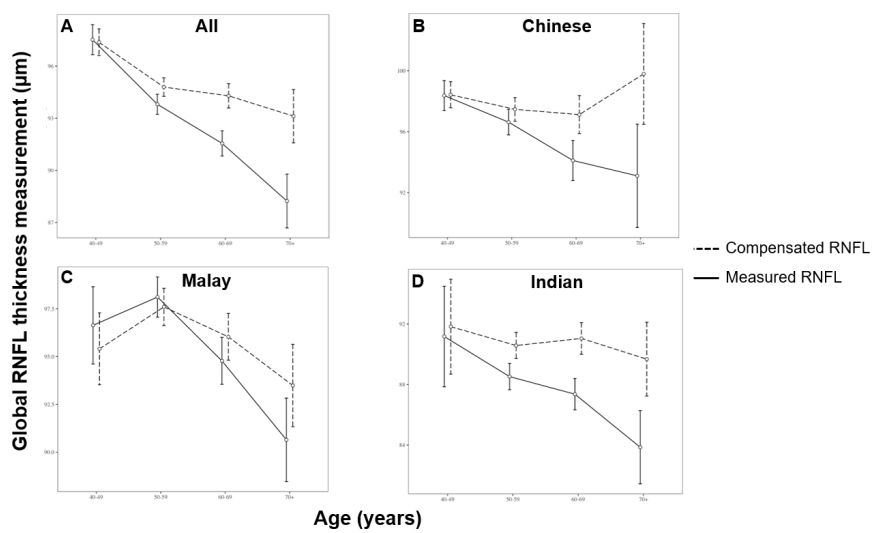

Figure 3 Distribution of measured and compensated RNFL thicknesses among participants of varying age groups and ethnicity. Compensation reduced the age-related RNFL decline by $55 \%$ in $(\mathrm{A})$ all participants, where the greatest reduction was among the (B) Chinese (93\%), followed by (D) Indians (79\%) and then (C) Malays (59\%). RNFL, retinal nerve fibre layer.

thinner CCT, reduced density of retinal vessels, long-sightedness, shorter axial length, and thinner measured and corrected RNFL ( $p$ trends <0.05). Figure 2 further showed the distribution of retinal vessel density among the varying age groups. For every 1 year increase in age, there was a $-28.09 \mu \mathrm{m}$ reduction in retinal vessel density in the overall population (95\% CI -38.23 to 17.96; $\mathrm{p}<0.001)$.

Coefficients of variation of measured and compensated RNFL thicknesses were compared in each of four quadrants, stratified by ethnicity (table 3 ). Compensation reduced the variability of global RNFL in the overall Asian population (9.6\%; $\mathrm{p}<0.001$ ), where the greatest improvement was found for the temporal quadrant (11.8\%), followed by the superior quadrant $(9.3 \%)$, inferior quadrant $(8.9 \%)$ and, lastly, nasal quadrant $(8.1 \%$; all $\mathrm{p}<0.001)$. In terms of ethnicity, the effect was greatest among the Chinese $(10.9 \% ; \mathrm{p}<0.001)$, followed by Malays $(6.6 \%$; $\mathrm{p}=0.075)$ and then Indians $(4.3 \% ; \mathrm{p}=0.192)$.

Online supplementary table shows the univariate linear regression of demographic and clinical factors on measured and compensated RNFL, stratified by ethnicity. Age was negatively correlated with measured and compensated RNFL thicknesses in the overall population $(\beta=-3.32 \mu \mathrm{m} ; \mathrm{p}<0.001$ vs $\beta=-1.50 \mu \mathrm{m}$; $\mathrm{p}=0.004)$ and Malays $(\beta=-2.83 \mu \mathrm{m} ; \mathrm{p}<0.001 \mathrm{vs} \beta=-1.17 \mu \mathrm{m}$; $\mathrm{p}=0.004)$ whereas age was only correlated with measured RNFL and not with compensated RNFL for Chinese $(\beta=-2.26 \mu \mathrm{m}$; $\mathrm{p}<0.001$ vs $\beta=-0.16 \mu \mathrm{m} ; \mathrm{p}=0.666)$ and Indians $(\beta=-2.33 \mu \mathrm{m}$; $\mathrm{p}<0.001$ vs $\beta=-0.49 \mu \mathrm{m} ; \mathrm{p}=0.258)$. Compensation reduced the age-related RNFL decline by $55 \%$ in the overall population $(\beta=-3.32 \mu \mathrm{m}$ vs $\beta=-1.50 \mu \mathrm{m} / 10$ years; $p<0.001)$, where the greatest reduction was among the Chinese $(93 \% ; \beta=-2.26$ $\mu \mathrm{m}$ vs $\beta=-0.16 \mu \mathrm{m} / 10$ years; $\mathrm{p}<0.001)$, followed by Indians (79\%; $\beta=-2.33 \mu \mathrm{m}$ vs $\beta=-0.49 \mu \mathrm{m} / 10$ years; $p=0.005)$ and then Malays $(59 \% ; \beta=-2.83 \mu \mathrm{m}$ vs $\beta=-1.17 \mu \mathrm{m} / 10$ years; $\mathrm{p}=0.002$ ). Figure 3 further showed the distribution of measured and compensated RNFL thicknesses among the varying age groups, stratified by ethnicity.

In Chinese (online Supplementary table), refractive error, optic disc (area and orientation), fovea distance and retina vessel density were correlated with measured RNFL ( $\mathrm{p}<0.001)$. However, optic disc ratio and fovea angle were not associated with measured RNFL. Optic disc (area and orientation), fovea distance and retinal vessel density were no longer correlated 




Figure 4 Classification of individuals based on their measured and compensated RNFL thicknesses into three categories, stratified by varying quadrants. First category, those within the $95 \%$ normal limits, considered as normal (green category); second category, those outside the $95 \%$ normal limits but within the $99 \%$ normal limits, considered as suspect (yellow category); and third category, those outside of $99 \%$, considered as abnormal (red category). RNFL, retinal nerve fibre layer.

with compensated RNFL. Although refractive error remained correlated with compensated RNFL, compensation attenuated the effect of refractive error by $69 \%$ ( $\beta=0.98 \mu \mathrm{m}$ vs $\beta=0.30$ $\mu \mathrm{m} ; \mathrm{p}<0.001)$.

In Malays (online supplementary table), corneal curvature, refractive error, fovea distance, optic disc area and retinal vessel density were correlated with measured RNFL $(\mathrm{p}<0.05)$. Optic disc (ratio and orientation) and fovea angle were not associated with measured RNFL. Refractive error and retinal vessel density were no longer correlated with compensated RNFL. Corneal curvature, optic disc area and fovea distance remained correlated with compensated RNFL.

In Indians (online supplementary table), refractive error, optic disc area and retinal vessel density were correlated with measured RNFL ( $\mathrm{p}<0.05)$, but not optic disc (ratio and orientation) and fovea (distance and angle). Refractive error and retinal vessel density were no longer correlated with compensated RNFL. Optic disc area remained correlated with compensated RNFL.

Figure 4 shows the impact of compensation on the reclassification of individuals into varying categories of RNFL thickness measurements, stratified by RNFL quadrants. Out of 2563 subjects who were initially classified as normal when using OCT, $0.6 \%$ (global RNFL; $\mathrm{n}=17$ ), $0.7 \%$ (inferior RNFL; $\mathrm{n}=17$ ), $1.0 \%$ (superior RNFL; $n=24$ ), $1.5 \%$ (nasal RNFL; $n=39$ ) and $1.5 \%$ (temporal RNFL; $\mathrm{n}=39$ ) were reclassified as having RNFL falling outside of $95 \%$ normal limits after compensation. Out of 27 subjects who were classified as abnormal when using OCT, $55.6 \%$ (global RNFL; $\mathrm{n}=15$ ), 59.3\% (inferior RNFL; $\mathrm{n}=16$ ), 40.7\% (superior RNFL; $\mathrm{n}=11$ ), $81.5 \%$ (nasal RNFL; $\mathrm{n}=22$ ) and $74.1 \%$ (temporal RNFL; $\mathrm{n}=20$ ) were reclassified as having RNFL falling within $99 \%$ of normal limits after compensation. Figure 5 shows examples of three individuals where compensation of ocular anatomical parameters altered RNFL thickness measurements, from having 'an abnormally thinned RNFL' to 'normal RNFL'.

\section{DISCUSSION}

In this multiethnic, population-based study of adult Chinese, Malays and Indians in Singapore, we demonstrated an overall reduction in the interindividual variability of RNFL thickness after compensating for various anatomical parameters. The effect was greatest for Chinese, followed by Malays and then Indians. This highlights the potential advantages of using compensated RNFL values for clinical use such as early diagnosis of glaucomatous damage, which may be gained by compensating away measurement variability influenced by anatomical parameters. Our study indicated that compensation of RNFL thickness measurements for anatomical parameters may improve diagnostic performance in different ethnicities. Importantly, RNFL thickness measurement is not limited to glaucoma, but has also been useful in diseases such as non-arteritic ischaemic optic neuropathy, ${ }^{34}$ Parkinson's disease, ${ }^{35}$ Alzheimer's disease ${ }^{36}$ and multiple sclerosis. ${ }^{37}$

We report several findings that are important in advancing our understanding of the measurement of RNFL thickness with SD-OCT imaging. Even though the current model reduced the interindividual variability in Asians, several observations indicate that a more refined model will be required. First, our model improved the RNFL measurement variability most effectively in Chinese and least effectively in Indians. Given that the age and refraction distribution in Chinese, Malays and Indians were different, it is plausible that compensation of RNFL thickness had a higher impact in Chinese because they were younger and had higher degrees of myopia. Second, certain anatomical features known to affect RNFL measurements remained associated with compensated RNFL. One such example is refractive error, where it remained associated with compensated RNFL in Chinese. This may be because the initial model was developed in Caucasians ${ }^{13}$ with lower incidence of myopia than the Chinese. ${ }^{20}$ Therefore, accounting for a wider range of refractive error in the new model would be important, in particular of the rapidly increasing prevalence of myopia globally, ${ }^{38}$ and the diagnostic challenges with glaucoma presented by highly myopic eyes. ${ }^{39}$ Third, new anatomical features such as corneal curvature may be needed as it was associated with RNFL in Malays. Studies have shown that corneal curvature can have a magnification effect on RNFL measurements ${ }^{40} 41$ and should be considered in the new model. Overall, future models will need to account for a wider range of existing parameters and include new anatomical features to better compensate away RNFL measurement variability influenced by anatomical parameters, which would provide better sensitivity and specificity for glaucoma detection.

Age-related decline in measured RNFL was greatly attenuated by $\sim 55 \%$ for global RNFL in the overall population after accounting for anatomical factors. One of the most likely explanations is that OCT is not able to differentiate retinal vessels from neuronal axons. Hence, the RNFL thickness measurement will include retinal vessels. Age-related decline in RNFL thickness has been reported in studies ${ }^{42} 43$ and may therefore represent to a large degree a change in retinal vasculature. Using Cirrus SD-OCT, Leung et al showed a significant negative correlation between age and measured RNFL thickness $(-0.33 \mu \mathrm{m} / \mathrm{year}$; $\mathrm{p}=0.011),{ }^{43}$ which was comparable to our findings in the overall population $(-0.33 \mu \mathrm{m} /$ year; $\mathrm{p}<0.001)$. However, compensating for anatomical factors reduced this age-related decline in RNFL thickness as much as $50 \%(-0.15 \mu \mathrm{m} /$ year; $\mathrm{p}<0.001)$. This suggests that age-related ocular parameters such as retinal vessels should be accounted for when using RNFL measurements for diagnostic purpose as well as in OCT-related longitudinal glaucoma studies. Our results are compatible with previous reports on the age-related reduction of retinal vessels ${ }^{44}$ and retinal blood flow with age. ${ }^{45}$ Moreover, glaucomatous optic neuropathy is also associated with a loss of retinal microvessels and retinal perfusion deficits. ${ }^{46-52}$ Hence, compensation of RNFL thickness measurements for anatomical parameters may be important for glaucoma eyes. 

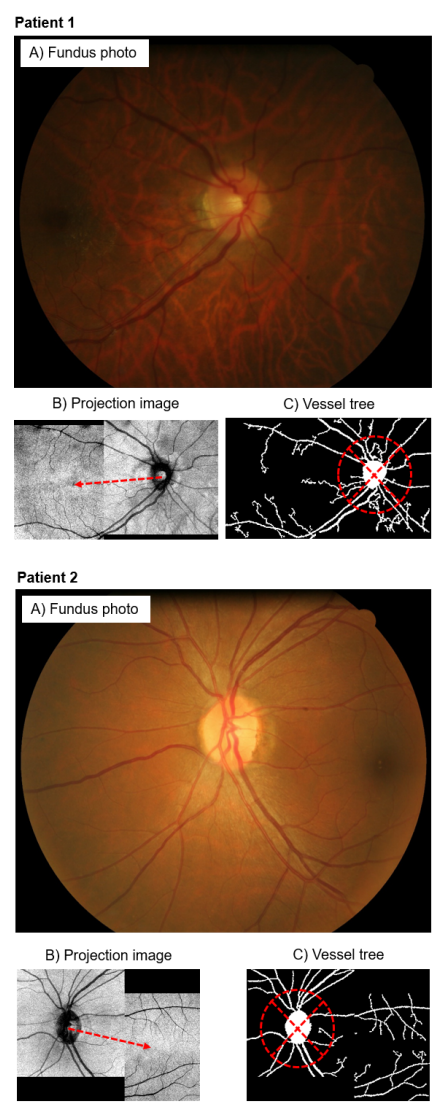

Patient 3

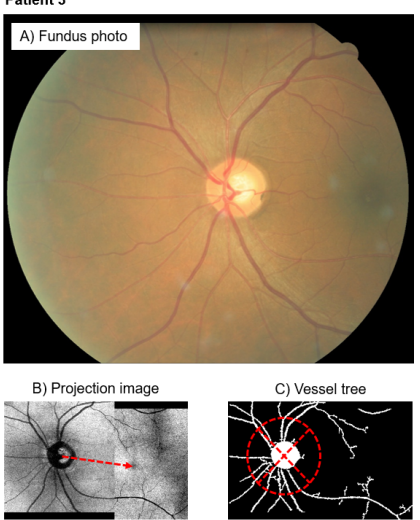

D) RNFL Thicknoss Map E) RNFL Dovition M

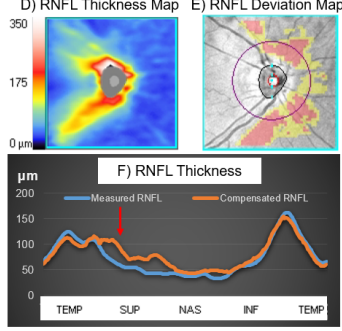

Characteristics
Measured RNFL @ Superior Quadrant Measured RNFL @ Superior Quadrant
Compensated RNFL @ Superilor Quadrant Difference RNFL (Measured - Compensated) Spherical Equivalent

Optic Disc Ratio (Elliptical; 1.0 is effectively round) pptic Disc Area (smaller)
Optic Disc Orientation Optic Disc Orientatlon
Disc-Fovea Distance

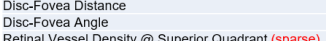

D) RNFL Thickness Map E) RNFL Dovintion Ma

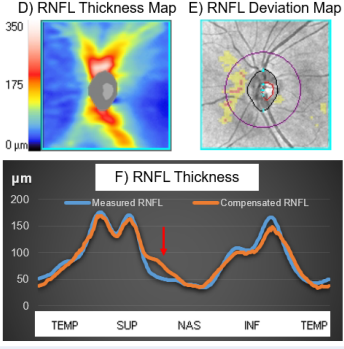

Characteristics
Measured RNFL @ Nasal Quadrant Measured RNFL @ Nasal Quadrant
Compensated RNFL @ Nasal Quadrant Compensated RNFL @ Nasal Quadrant
Difference RNFL (Measured - Compensated) Spherical Equivalent

Optic Disc Ratio (Elliptical; 1.0 is effectively round) Optic Disc Area
Optic Disc Orientation Optlc Disc Orientation
Disc-Fovea Distance

Detinal Vessel Density @ Nasal Quadrant (sparse
Disc-Fove Angle (angled
Retal

D) RNFL Thickness Map E) RNFL Doviation Map

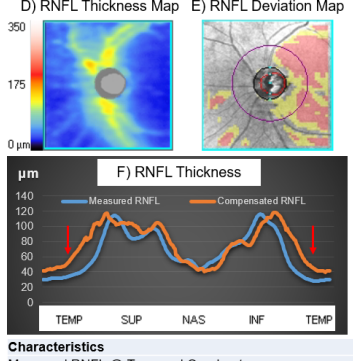

Characteristics Compensated RNFL @ Temporal Quadrant
Difference RNFL (Measured - Compensated) Difference RNFL (Measured - Compensated)
Spherical Equivalent Sphencal Equivalent Optic Disc Ratio
Optic Disc Area
optic Disc Orient Optic Disc Orientation
Disc-Fovea Distance Disc-Fovea Distance Disc-Fovea Angle (angled)
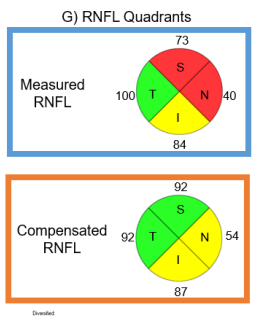

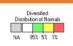
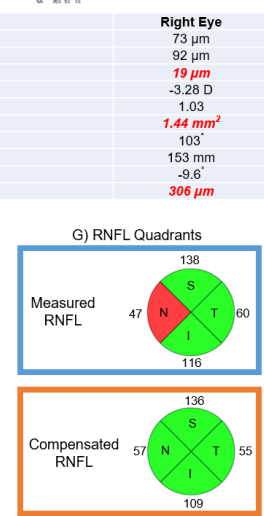

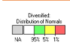
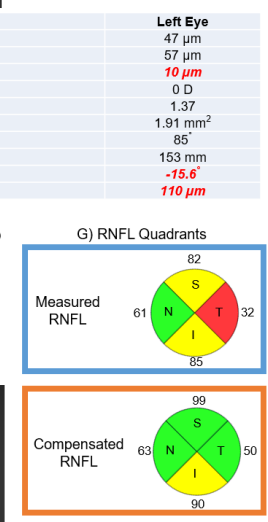

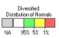

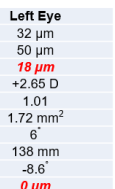

Figure 5 Three examples of participants who went from having an abnormally thinned RNFL at the superior (patient 1), nasal (patient 2) and temporal (patient 3) quadrants to a normal RNFL. Patient 1 is a 61-year-old woman, where compensation of anatomical parameters increased the RNFL thickness measurement in the superior quadrant of the right eye by $19 \mu \mathrm{m}$. (A-C) Fundus photo, optical coherence tomography (OCT) projection image and binarised image of the vessel tree showing a small optic disc area $\left(1.44 \mathrm{~mm}^{2}\right)$ and slightly sparse retinal vessels at superior quadrant $(306 \mu \mathrm{m})$. (D, E) OCT RNFL thickness and deviation map showing a thinned RNFL thickness at superior quadrant. (F) RNFL circumpapillary thickness line graph showing a thicker compensated RNFL than measured RNFL, especially the superior quadrant (red arrows). (G) RNFL quadrant hours showing a thinned measured RNFL at superior quadrant, falling in the red zone, indicating outside the $99 \%$ distribution. After compensation, compensated RNFL of the superior quadrant now falls in the green zone, indicating it is within the $95 \%$ distribution. Patient 2 is a 50 -year-old woman, where compensation of anatomical parameters increased the RNFL thickness measurement in the nasal quadrant of the left eye by $10 \mu \mathrm{m}$. (A-C) Fundus photo, OCT projection image and binarised image of the vessel tree showing a great optic disc-fovea angle $\left(-15.6^{\circ}\right)($ red arrow) and sparse retinal vessels at nasal quadrant $(110 \mu \mathrm{m})$. (D, E) OCT RNFL thickness and deviation map showing a thinned RNFL thickness at nasal quadrant. (F) RNFL circumpapillary thickness line graph showing a thicker compensated RNFL than measured RNFL, especially the nasal quadrant (red arrow). (G) RNFL quadrant hours showing a thinned measured RNFL at nasal quadrant, falling in the red zone, indicating outside the $99 \%$ distribution. After compensation, compensated RNFL of the nasal quadrant now falls in the green zone, indicating it is within the $95 \%$ distribution. Patient 3 is a 67-year-old man, where compensation of anatomical parameters increased the RNFL thickness measurement in the temporal quadrant of the left eye by $18 \mu \mathrm{m}$. (A-C) Fundus photo, OCT projection image and binarised image of the vessel tree showing sparser retinal vessels at temporal quadrant (0 $\mu \mathrm{m})$. (D, E) OCT RNFL thickness and deviation map showing a thinned RNFL thickness at temporal quadrant. (F) RNFL circumpapillary thickness line graph showing a thicker compensated RNFL than measured RNFL, especially the temporal quadrant (red arrows). (G) RNFL quadrant hours showing a thinned measured RNFL at temporal quadrant, falling in the red zone, indicating outside the $99 \%$ distribution. After compensation, compensated RNFL of the temporal quadrant now falls in the green zone, indicating it is within the $95 \%$ distribution. RNFL, retinal nerve fibre layer. 
Our model reclassified $\sim 62 \%$ of abnormal individuals out of the 'at risk category' and $\sim 1 \%$ of normal individuals into the 'at risk category'. This meant that at least $62 \%$ of those who were initially considered as having thinned RNFL by conventional OCT in fact only appeared to have thinned RNFL as a result of anatomical variations (figure 4). This is clinically relevant as well as impactful in the management of patients with glaucoma. Differentiating between normal and early glaucoma is often difficult and clinicians often rely on structural OCT imaging to give an objective assessment of the RNFL before determining if treatment or closer monitoring for glaucoma should be carried out. Our comprehensive model, which comprises precise alignments, vessel removal and input of patient's anatomical features to OCT scans before sectorial analysis, would therefore allow the accurate identification of glaucoma suspects.

\section{Strengths and limitations}

The strengths of this study included the large, multiethnic Asian population-based sample size of eyes without ocular diseases. Thus, we believe that the findings represent population variations of RNFL thickness in different ethnicities. In addition, our study adopted standardised OCT imaging, thus allowing relatively direct and objective comparisons across the ethnic groups. In this study, the compensation was done with one specific OCT device, it can in principle be applied to OCT machines from other companies. Our study had a few limitations. First, OCT imaging was introduced halfway into the study, hence fewer Chinese underwent OCT imaging compared with Malays or Indians. Second, owing to the cross-sectional nature of our study, we could identify an attenuation in the age-related decline in RNFL thickness after compensation, but is not able to address the temporal relationship. Longitudinal data in normal eyes are needed to clarify this relationship. Third, the current model was employed for RNFL measurements only, but not for macular measures of glaucoma damage such as retinal ganglion cell complex. ${ }^{53}$ Based on our results it is likely that the interindividual variability of such measures will also be reduced by anatomical compensation, although additional studies are required to prove this hypothesis. Most importantly, our compensation model of RNFL thickness is not perfect; it provided a simplified correction of potential anatomical parameters that are related to RNFL thickness. We have only considered for optic disc (ratio, orientation and area), fovea (distance and angle), retinal vessel density, refractive error and age. Other underlying causes of interindividual variability of RNFL might be due to age-related optic nerve head changes, vessel geometry or posterior sclera changes.

In conclusion, we have demonstrated that RNFL thickness compensated for ocular biometry and morphology had major impact on healthy subjects. The greatest effect was observed in Chinese, and least effective in Indians. Anatomical compensation should be considered when refining the RNFL normative database, which may improve glaucoma diagnosis.

\footnotetext{
Author affiliations

${ }^{1}$ Singapore Eye Research Institute, Singapore National Eye Centre, Singapore, Singapore

${ }^{2}$ Section for Medical Information Management and Imaging, Center for Medical Statistics, Informatics and Intelligent Systems, Medical University of Vienna, Vienna, Austria

${ }^{3}$ Ocular Epidemiology Research Group, Singapore Eye Research Institute, Singapore, Singapore

${ }^{4}$ Ophthalmology and Visual Sciences, The Chinese University of Hong Kong, Ma Liu Shui, Hong Kong

${ }^{5}$ Singapore National Eye Centre, Singapore, Singapore

${ }^{6}$ Ophthalmology, Medical University of Vienna, Vienna, Austria

${ }^{7}$ Department of Clinical Pharmacology, Medical University of Vienna, Vienna, Austria
}

Contributors All the authors met the four criteria of contributorship. Acquisition, analysis or interpretation of data: all authors. Drafting of the manuscript: JC, LS. Critical revision of the manuscript for important intellectual content: all authors. Statistical analysis: DQN, JC. Obtained funding: LS, CYC. Administrative, technical or material support: all authors. Study supervision: LS, JC, FS and CV prepared and reviewed the main manuscript, tables and figures.

Funding This work was funded by grants from the National Medical Research Council, Singapore (CG/C010A/2017; CG/SERI/2010; STaR/0003/2008; CIRG/1417/2015; CIRG/1488/2018; OFLCG/004a/2018).

Disclaimer The sponsor or funding organisation had no role in the design or conduct of this research.

Competing interests None declared.

Patient consent for publication Not required.

Ethics approval SingHealth Centralized Institutional Review Board.

Provenance and peer review Not commissioned; externally peer reviewed.

Data availability statement All data relevant to the study are included in the article or uploaded as supplementary information.

Open access This is an open access article distributed in accordance with the Creative Commons Attribution Non Commercial (CC BY-NC 4.0) license, which permits others to distribute, remix, adapt, build upon this work non-commercially, and license their derivative works on different terms, provided the original work is properly cited, appropriate credit is given, any changes made indicated, and the use is non-commercial. See: http://creativecommons.org/licenses/by-nc/4.0/.

\section{ORCID iDs}

Jacqueline Chua http://orcid.org/0000-0002-6474-5293

Carol Cheung http://orcid.org/0000-0002-9672-1819

Ching-Yu Cheng http://orcid.org/0000-0002-4916-6074

Leopold Schmetterer http://orcid.org/0000-0002-7189-1707

\section{REFERENCES}

1 Tham Y-C, Li X, Wong TY, et al. Global prevalence of glaucoma and projections of glaucoma burden through 2040: a systematic review and meta-analysis. Ophthalmology 2014;121:2081-90.

2 Hood DC. Improving our understanding, and detection, of glaucomatous damage: an approach based upon optical coherence tomography (OCT). Prog Retin Eye Res 2017:57:46-75.

3 Oddone F, Lucenteforte $\mathrm{E}$, Michelessi M, et al. Macular versus retinal nerve fiber layer parameters for diagnosing manifest glaucoma: a systematic review of diagnostic accuracy studies. Ophthalmology 2016;123:939-49.

4 Amini N, Nowroozizadeh S, Cirineo N, et al. Influence of the disc-fovea angle on limits of RNFL variability and glaucoma discrimination. Invest Ophthalmo/ Vis Sci 2014;55:7332-42.

5 Jonas RA, Wang YX, Yang H, et al. Optic Disc - Fovea Angle: The Beijing Eye Study 2011. PLoS One 2015;10:e0141771.

6 Resch H, Pereira I, Hienert J, et al. Influence of disc-fovea angle and retinal blood vessels on interindividual variability of Circumpapillary retinal nerve fibre layer. $\mathrm{Br} J$ Ophthalmol 2016:100:531-6.

7 Wang $\mathrm{M}$, Jin Q, Wang $\mathrm{H}$, et al. The interrelationship between refractive error, blood vessel anatomy, and glaucomatous visual field loss. Trans/ Vis Sci Technol 2018;7.

8 Yamashita T, Asaoka R, Tanaka M, et al. Relationship between position of peak retinal nerve fiber layer thickness and retinal arteries on sectoral retinal nerve fiber layer thickness. Invest Ophthalmo/ Vis Sci 2013;54:5481-8.

9 Baniasadi N, Wang M, Wang H, et al. Associations between optic nerve Head-Related anatomical parameters and refractive error over the full range of glaucoma severity. Trans/ Vis Sci Technol 2017;6

10 Savini G, Barboni P, Parisi V, et al. The influence of axial length on retinal nerve fibre layer thickness and optic-disc size measurements by spectral-domain OCT. Br J Ophthalmol 2012;96:57-61.

11 Wong TY, Klein R, Sharrett AR, et al. The prevalence and risk factors of retinal microvascular abnormalities in older persons: the Cardiovascular Health study. Ophthalmology 2003;110:658-66.

12 Radcliffe NM, Smith SD, Syed ZA, et al. Retinal blood vessel positional shifts and glaucoma progression. Ophthalmology 2014;121:842-8.

13 Pereira I, Resch H, Schwarzhans F, et al. Multivariate model of the intersubject variability of the retinal nerve fiber layer thickness in healthy subjects. Invest Ophthalmol Vis Sci 2015;56:5290-8.

14 Chua J, Tham YC, Liao J, et al. Ethnic differences of intraocular pressure and central corneal thickness: the Singapore epidemiology of eye diseases study. Ophthalmology 2014;121:2013-22.

15 Narayanaswamy A, Chung RS, Wu R-Y, et al. Determinants of corneal biomechanical properties in an adult Chinese population. Ophthalmology 2011;118:1253-9.

16 Chua J, Nongpiur ME, Zhao W, et al. Comparison of corneal biomechanical properties between Indian and Chinese adults. Ophthalmology 2017;124:1271-9. 
$17 \mathrm{Ho} \mathrm{H}$, Tham YC, Chee ML, et al. Retinal nerve fiber layer thickness in a multiethnic normal Asian population: the Singapore epidemiology of eye diseases study. Ophthalmology 2019;126:702-11.

18 Wong KH, Tham Y-C, Nguyen DQ, et al. Racial differences and determinants of macular thickness profiles in multiethnic Asian population: the Singapore epidemiology of eye diseases study. Br J Ophthalmol 2019;103:894-9.

19 Li X, Wong WL, Cheung CY-L, et al. Racial differences in retinal vessel geometric characteristics: a multiethnic study in healthy Asians. Invest Ophthalmol Vis Sci 2013;54:3650-6.

20 Pan C-W, Zheng Y-F, Anuar AR, et al. Prevalence of refractive errors in a multiethnic Asian population: the Singapore epidemiology of eye Disease Study. Invest Ophthalmol Vis Sci 2013;54:2590-8.

21 Lavanya R, Jeganathan VSE, Zheng Y, et al. Methodology of the Singapore Indian Chinese cohort (SICC) eye study: quantifying ethnic variations in the epidemiology of eye diseases in Asians. Ophthalmic Epidemiol 2009;16:325-36.

22 Rosman M, Zheng Y, Wong W, et al. Singapore Malay eye study: rationale and methodology of 6-year follow-up study (SiMES-2). Clin Exp Ophthalmol 2012;40:557-68.

23 Sabanayagam C, Yip W, Gupta P, et al. Singapore Indian eye Study-2: methodology and impact of migration on systemic and eye outcomes. Clin Exp Ophthalmol 2017:45:779-89.

24 Chua J, Chee ML, Chin CWL, et al. Inter-relationship between ageing, body mass index, diabetes, systemic blood pressure and intraocular pressure in Asians: 6-year longitudinal study. Br J Ophthalmol 2019;103:196-202.

25 Koh V, Tham Y-C, Cheung CY, et al. Diagnostic accuracy of macular ganglion cell-inner plexiform layer thickness for glaucoma detection in a population-based study: comparison with optic nerve head imaging parameters. PLoS One 2018;13:e0199134.

26 Abràmoff MD, Garvin MK, Sonka M. Retinal imaging and image analysis. IEEE Rev Biomed Eng 2010;3:169-208.

27 Li K, Wu X, Chen DZ, et al. Optimal surface segmentation in volumetric images--a graph-theoretic approach. IEEE Trans Pattern Anal Mach Intell 2006;28:119-34.

28 Zhang L, Buitendijk GHS, Lee K, et al. Validity of automated choroidal segmentation in SS-OCT and SD-OCT. Invest Ophthalmol Vis Sci 2015;56:3202-11.

29 Smith SW. The scientist and engineer's guide to digital signal processing. California Technical Publishing, 2002.

30 Pereira I, Weber S, Holzer S, et al. Correlation between retinal vessel density profile and Circumpapillary RNFL thickness measured with Fourier-domain optical coherence tomography. Br J Ophthalmol 2014;98:538-43.

31 Shen SY, Wong TY, Foster PJ, et al. The prevalence and types of glaucoma in Malay people: the Singapore Malay eye study. Invest Ophthalmol Vis Sci 2008;49:3846-51.

32 Wong TY, Cheung N, Tay WT, et al. Prevalence and risk factors for diabetic retinopathy: the Singapore Malay eye study. Ophthalmology 2008;115:1869-75.

33 Kawasaki R, Wang JJ, Aung T, et al. Prevalence of age-related macular degeneration in a Malay population: the Singapore Malay eye study. Ophthalmology 2008;115:1735-41.

34 Bellusci C, Savini G, Carbonelli M, et al. Retinal nerve fiber layer thickness in nonarteritic anterior ischemic optic neuropathy: OCT characterization of the acute and resolving phases. Graefes Arch Clin Exp Ophthalmol 2008;246:641-7.
35 Yu J-G, Feng Y-F, Xiang Y, et al. Retinal nerve fiber layer thickness changes in Parkinson disease: a meta-analysis. PLoS One 2014;9:e85718.

36 Chan VTT, Sun Z, Tang S, et al. Spectral-domain OCT measurements in Alzheimer's disease: a systematic review and meta-analysis. Ophthalmology 2019;126.

37 Petzold A, Balcer LJ, Calabresi PA, et al. Retinal layer segmentation in multiple sclerosis: a systematic review and meta-analysis. Lancet Neurol 2017;16:797-812.

38 Holden BA, Fricke TR, Wilson DA, et al. Global prevalence of myopia and high myopia and temporal trends from 2000 through 2050. Ophthalmology 2016;123:1036-42.

$39 \mathrm{Ng}$ DSC, Cheung CYL, Luk FO, et al. Advances of optical coherence tomography in myopia and pathologic myopia. Eye 2016;30:901-16.

40 Higashide T, Ohkubo S, Hangai M, et al. Influence of clinical factors and magnification correction on normal thickness profiles of macular retinal layers using optical coherence tomography. PLoS One 2016;11:e0147782.

41 Hirasawa K, Shoji N. Influence of corneal power on Circumpapillary retinal nerve fiber layer and optic nerve head measurements by spectral-domain optical coherence tomography. Int J Ophthalmol 2017;10:1385-91.

42 Parikh RS, Parikh SR, Sekhar GC, et al. Normal age-related decay of retinal nerve fiber layer thickness. Ophthalmology 2007;114:921-6.

43 Leung CKS, Yu M, Weinreb RN, et al. Retinal nerve fiber layer imaging with spectraldomain optical coherence tomography: a prospective analysis of age-related loss. Ophthalmology 2012;119:731-7.

44 Wong TY, Klein R, Klein BEK, et al. Retinal vessel diameters and their associations with age and blood pressure. Invest Ophthalmol Vis Sci 2003;44:4644-50.

45 Groh MJ, Michelson G, Langhans MJ, et al. Influence of age on retinal and optic nerve head blood circulation. Ophthalmology 1996;103:529-34

46 Geyman LS, Garg RA, Suwan Y, et al. Peripapillary perfused capillary density in primary open-angle glaucoma across disease stage: an optical coherence tomography angiography study. Br J Ophthalmol 2017;101:1261-8.

47 Chihara E, Dimitrova G, Amano H, et al. Discriminatory power of superficial vessel density and Prelaminar vascular flow index in eyes with glaucoma and ocular hypertension and normal eyes. Invest Ophthalmol Vis Sci 2017;58:690-7.

48 Triolo G, Rabiolo A, Shemonski ND, et al. Optical coherence tomography angiography macular and peripapillary vessel perfusion density in healthy subjects, glaucoma suspects, and glaucoma patients. Invest Ophthalmol Vis Sci 2017;58:5713-22.

49 Shoji T, Zangwill LM, Akagi T, et al. Progressive macula vessel density loss in primary open-angle glaucoma: a longitudinal study. Am J Ophthalmol 2017;182:107-17.

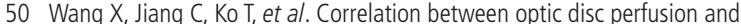
glaucomatous severity in patients with open-angle glaucoma: an optical coherence tomography angiography study. Graefes Arch Clin Exp Ophthalmo 2015;253:1557-64.

51 Rao HL, Pradhan ZS, Weinreb RN, et al. Regional comparisons of optical coherence tomography angiography vessel density in primary open-angle glaucoma. Am J Ophthalmol 2016;171:75-83.

52 Kiyota N, Kunikata H, Takahashi S, et al. Factors associated with deep circulation in the peripapillary chorioretinal atrophy zone in normal-tension glaucoma with myopic disc. Acta Ophthalmol 2018;96:e290-7.

53 Hood DC, Raza AS, de Moraes CGV, et al. Glaucomatous damage of the macula. Prog Retin Eye Res 2013:32:1-21. 